\title{
A Study On Profitability Indicators Of Housing Finance Companies In India
}

\author{
Pathma Priya.D ${ }^{1}$, Dr.P.Rengarajan ${ }^{2}$ \\ ${ }^{1}$ (Research scholar, Department of Commerce, Vidyasagar College of Arts and Science, India) \\ ${ }^{2}$ (Assistant Professor, Department of Commerce, Poompuhar College, India)
}

\begin{abstract}
This paper attempts to analyse the profitability indicators of housing finance companies in India. Housing is one of the basic human needs and is second to the need for food and clothing. Feeling of having own house is a matter of immense pleasure for everyone. The need for purchase or construct a house brought out specialized housing finance institutions. Housing finance institutions play an important role in the Indian housing finance system. So there is a need to analyse the profitability of housing finance companies. The study is based on secondary data. Secondary data were collected from the CAPITALINE DATABASES for the year 2010-2011 to 2014-2015. The profitability indicators like Net Profit, Total Assets, Operating and Administrative Expenses, Employee Expenses and Spread for the select housing finance companies in India are measured by using statistical tools such as Mean, Standard Deviation, Coefficient of Variation and Trend.
\end{abstract}

Key Words: Housing, Housing Finance, Housing Finance Companies, Profitability Indicators.

\section{Introduction}

Housing is one of the basic human needs. Housing is an important component for the measure of socioeconomic status of the people. The demand for housing is increasing day by day due to the arithmetic progression of population, the migration of people from rural areas to urban areas for employment, increase in disposable income level, increasing number of nuclear families and etc., With the increase in demand the of financing the purchasing of a house came up. All the public, private, foreign, co-operative banks and financial institutions provide home loans to the people who want to purchase or build a house through home loan. The significant emphasis had been made in institutional set up for housing finance in form of specialized housing finance institutions. The RBI regulates commercial banks, while the NHB regulates the housing finance companies. Initially the housing finance companies played a major role in providing housing finance to the people. After the entry of banking sector and other players in this field, the scenario started changing.

\section{Review Of Literature}

Aswin Kumar Bhalla et.al., (2009) in their research paper entitled "Profitability of Housing Finance Companies In India: A Bivariate Analysis of Selected HFCs" analyzed that the financial performance of selected housing finance companies and examined the effect of various independent variables like., interest income, interest expenses, non-interest income, operating and administrative expenses and employee costs on profitability of these companies. Various financial measures and financial ratios were used to analyse the performance of these companies. Return on capital employed is a good measure of profitability in as much as in is an extension of the input - output analysis. The study concluded that HFCs have to spread out geographically while ensuring consistency in the processing and service standards.

Sohel Mehodi (2014) in his article entitled "Liquidity and Profitability Analysis: a Case Study of Delta Brac Housing Finance Corporation Limited", examined the liquidity and Profitability position of the Select Company. The collected data have been used for calculating financial ratios. These are analysed and interpreted by using some statistical tools like average, standard deviation, co-efficient of variation and t-test method. The period of the study is covered five years from 2008-2009 to 2012-2013. The study concluded that the company should be given emphasis in the field of working capital management.

\section{Objectives of the Study}

a) To analyse the profitability indicators of select housing finance companies in India.

b) To examine the trends in profitability of select housing finance companies.

\section{Scope of the Study}

The study is to identify the profit indicators of select housing finance companies in India i.e., LICHFL, HDFC Ltd, CANFIN Homes Ltd and GRUH Finance Ltd. It is mainly dealt with the components of profitability of these companies which evaluates the companies' performance. 
Period of Study

The study covers a period of five years from 2010-2011 to 2014-2015 is taken for the study.

\section{Methodology}

\subsection{Data Collection}

The study is based on secondary data. Information required for the study has been collected from the CAPITALINE DATABASES, annual report of LICHFL, HDFC Ltd, CANFIN Homes Ltd and GRUH Finance Ltd and different books, journals, magazines and data collected from various websites.

\subsection{Sample Design}

The study is done with special reference to both public and private sector of housing finance companies in India. The election of sample four companies LICHFL, CANFIN Homes Ltd, HDFC Ltd, and GRUH Finance Ltd is made on the basis of top 10 listed housing finance companies in India.

\subsection{Statistical Tools}

In this study various statistical tools are used such as Mean, Standard deviation, Coefficient of variation \& Trend analysis have been used for data analysis.

\section{Limitations of the Study}

a) The study is related to a period of five years, due to limited span of time only profitability indicators of select companies are taken for the study.

b) As the data are only secondary, i.e., they are collected from the published annual reports.

\section{Analysis Of Profitability Indicators}

Profit is the very reason for the continued existence of every commercial organization. The rate of profitability and volume of profits are therefore, rightly considered as the indicators of efficiency in the deployment of resources of the housing finance companies in India. There are a number of variables which measure the profitability indicators of select housing finance companies in India. The components of profitability i.e., net profit, total assets, operating and administrative expenses, employee expenses and spread of select companies is analysed. The mean, coefficient of variation and Trend of select companies are analyzed.

\subsection{Net Profit}

Net profit i.e., profit after tax is arrived at after deduction from out of the total income, all expenses and charges including depreciation and provision for tax. An efficient system generates profit which shows an increasing trend year after year.

TABLE: 4.1(a) Analysis of Mean and Coefficient of Variation

\begin{tabular}{|c|c|c|c|c|c|c|c|}
\hline \multicolumn{8}{|c|}{ Net profit } \\
\hline YEAR & 2011 & 2012 & 2013 & 2014 & 2015 & Average & $\mathrm{CV}$ \\
\hline LICHFL & 662.18 & 974.49 & 914.2 & 1023.22 & 1317.19 & 978.26 & 24.02 \\
\hline CANFIN & 39.19 & 42.01 & 43.76 & 54.12 & 75.71 & 50.96 & 29.32 \\
\hline HDFC & 2826.49 & 3534.96 & 4122.62 & 4848.34 & 5440.24 & 4154.53 & 24.91 \\
\hline GRUH & 68.96 & 91.51 & 120.34 & 145.88 & 176.96 & 120.73 & 35.45 \\
\hline Average & 899.21 & 1160.74 & 1300.23 & 1517.89 & 1752.53 & \multirow{2}{*}{\multicolumn{2}{|c|}{ 1326.12 }} \\
\hline $\mathrm{CV}$ & 146.41 & 141.27 & 147.84 & 149.08 & 143.91 & & \\
\hline
\end{tabular}

From the above table shows that the mean value of net profit for HDFC Ltd is the highest while the mean value Canfin Home Finance Ltd is the lowest. The mean value of net profit for the year 2015 is the highest and for the year 2011 mean value of net profit is the lowest.

The coefficient of variation for LIC Housing Finance Ltd is the least indicating that there is less variation in net profit over the study period 2011-2015 and the coefficient of variation for GRUH Finance Limited is the highest indicating that there is more variation in net profit over the study period 2011-2015. The coefficient of variation of net profit for the year 2012 is the lowest indicating that the year is more consistent and the coefficient of variation of net profit for the year 2014 is the highest indicating that the year is inconsistent. 
TABLE: 4.1(b) Trend Analysis in Net Profit

\begin{tabular}{|c|c|c|c|c|c|c|c|c|}
\hline \multirow[t]{2}{*}{ YEAR } & \multicolumn{2}{|c|}{ LICHFL } & \multicolumn{2}{|c|}{ CANFIN } & \multicolumn{2}{|c|}{ HDFC } & \multicolumn{2}{|l|}{ GRUH } \\
\hline & Amount (Rs.) & AGR & Amount (Rs.) & AGR & Amount (Rs.) & AGR & Amount (Rs.) & AGR \\
\hline 2011 & 662.18 & 0.00 & 39.19 & 0 & 2826.49 & 0 & 68.96 & 0 \\
\hline 2012 & 974.49 & 47.16 & 42.01 & 7.20 & 3534.96 & 25.07 & 91.51 & 32.70 \\
\hline 2013 & 914.2 & -6.19 & 43.76 & 4.17 & 4122.62 & 16.62 & 120.34 & 31.50 \\
\hline 2014 & 1023.22 & 11.93 & 54.12 & 23.67 & 4848.34 & 17.60 & 145.88 & 21.22 \\
\hline 2015 & 1317.19 & 28.73 & 75.71 & 39.89 & 5440.24 & 12.21 & 176.96 & 21.31 \\
\hline Average & & 16.33 & & 14.99 & & 14.30 & & 21.35 \\
\hline SD & & 21.78 & & 16.57 & & 9.23 & & 13.11 \\
\hline CV & & 133.41 & & 110.57 & & 64.57 & & 61.43 \\
\hline
\end{tabular}

The Table 4.1(b) explains the index of net profit has increased from base level of 0.00 to a maximum level of 47.16 in LICHFL, 39.89 in Can Fin Homes Ltd, 25.07 in HDFC Ltd and 32.70 in GRUH Fin Ltd. Of the select housing finance companies, the volume of net profit is in the positive trend except in the year 2013 index of LICHFL (-6.19).

\subsection{Total Assets}

The funds mobilized by various sources are deployed into the various assets by housing finance companies. Total assets depict the strength of the housing finance companies.

TABLE: 4.2(a) Analysis of Mean and Coefficient of Variation

\begin{tabular}{|c|c|c|c|c|c|c|c|}
\hline \multicolumn{8}{|c|}{ Total Assets } \\
\hline YEAR & 2011 & 2012 & 2013 & 2014 & 2015 & Average & $\mathrm{CV}$ \\
\hline LICHFL & 38145.83 & 49825.82 & 62420.72 & 75980.04 & 90363.88 & 63347.26 & 32.62 \\
\hline CANFIN & 2140.22 & 2228.89 & 2662.49 & 3963.05 & 5761.6 & 3351.25 & 45.71 \\
\hline HDFC & 12814.9 & 8805.24 & 7175.38 & 6982.73 & 7021.66 & 8559.98 & 29.17 \\
\hline GRUH & 2587.75 & 3313.1 & 4263.45 & 5466.23 & 7155.16 & 4557.14 & 39.69 \\
\hline Average & 13922.18 & 16043.26 & 19130.51 & 23098.01 & 27575.58 & \multirow{2}{*}{\multicolumn{2}{|c|}{19953.91}} \\
\hline CV & 121.28 & 141.52 & 151.17 & 152.72 & 151.81 & & \\
\hline
\end{tabular}

Table 4.2(a) shows that the mean value of total assets for LICHFL is the maximum, while the mean value CANFIN Home Finance Ltd is the minimum. The mean value of total assets for the year 2015 is the highest and for the year 2011 is the lowest.

The coefficient of variation for HDFC Ltd is the least indicating that there is less variation in total assets over the study period 2011-2015. The coefficient of variation for CANFIN Home Finance Ltd is the highest indicating that there is more variation in total assets over the study period 2011-2015. The coefficient of variation of total assets for the year 2011 is the lowest indicating that the year is more consistent and the coefficient of variation of total assets for the year 2015 is the highest indicating that the year is inconsistent.

TABLE: 4.2(b) Trend Analysis in Total Assets

\begin{tabular}{|r|r|r|r|r|r|r|r|r|}
\hline \multirow{2}{*}{ YEAR } & \multicolumn{2}{|c|}{ LICHFL } & \multicolumn{2}{c|}{ CANFIN } & \multicolumn{2}{c|}{ HDFC } & \multicolumn{2}{c|}{ GRUH } \\
\cline { 2 - 9 } & Amount (Rs.) & \multicolumn{1}{|c|}{ AGR } & Amount (Rs.) & \multicolumn{1}{c|}{ AGR } & \multicolumn{1}{c|}{ Amount (Rs.) } & \multicolumn{1}{c|}{ AGR } & Amount (Rs.) & \multicolumn{1}{c|}{ AGR } \\
\hline $\mathbf{2 0 1 1}$ & 38145.83 & 0 & 2140.22 & 0 & 12814.9 & 0 & 2587.75 & 0 \\
\hline $\mathbf{2 0 1 2}$ & 49825.82 & 30.62 & 2228.89 & 4.14 & 8805.24 & -31.29 & 3313.1 & 28.03 \\
\hline $\mathbf{2 0 1 3}$ & 62420.72 & 25.28 & 2662.49 & 19.45 & 7175.38 & -18.51 & 4263.45 & 28.68 \\
\hline $\mathbf{2 0 1 4}$ & 75980.04 & 21.72 & 3963.05 & 48.85 & 6982.73 & -2.68 & 5466.23 & 28.21 \\
\hline $\mathbf{2 0 1 5}$ & 90363.88 & 18.93 & 5761.6 & 45.38 & 7021.66 & 0.56 & 7155.16 & 30.90 \\
\hline Average & & $\mathbf{1 9 . 3 1}$ & & $\mathbf{2 3 . 5 7}$ & & $\mathbf{- 1 0 . 3 9}$ & $\mathbf{2 3 . 1 6}$ \\
\hline SD & & $\mathbf{1 1 . 6 4}$ & & $\mathbf{2 2 . 7 2}$ & & $\mathbf{1 4 . 0 5}$ & $\mathbf{1 3 . 0 0}$ \\
\hline CV & & $\mathbf{6 0 . 3 0}$ & & $\mathbf{9 6 . 4 1}$ & & $\mathbf{- 1 3 5 . 3 1}$ & \\
\hline
\end{tabular}

The Table 4.2(b) explains the trends in total assets has increased from base level of 0.00 to a maximum level of 30.62 in LICHFL, 48.85 in Can Fin Homes Ltd, 0.56 in HDFC Ltd and 30.90 in GRUH Fin Ltd. Whereas it has come down below the base year level for HDFC Ltd except in the year of $2015(0.56)$.

\subsection{Operating and Administrative Expenses}

The operating and administrative expenses include rent, rates and taxes, repairs and maintenance, electricity charges, insurance, general office expenses, travelling and conveyance, printing and stationery, postage, telephone expenses, advertising and others of housing finance companies. 
TABLE: 4.3(a) Analysis of Mean and Coefficient of Variation

\begin{tabular}{|c|c|c|c|c|c|c|c|}
\hline \multicolumn{8}{|c|}{ Operating and Administrative Expenses } \\
\hline YEAR & 2011 & 2012 & 2013 & 2014 & 2015 & Average & $\mathbf{C V}$ \\
\hline LICHFL & 121.23 & 136.56 & 158.8 & 184.46 & 198.95 & 160 & 20.18 \\
\hline CANFIN & 5.31 & 5.94 & 8.58 & 15.61 & 19.71 & 11.03 & 57.51 \\
\hline HDFC & 147.91 & 144.2 & 159.94 & 197.84 & 224.19 & 174.82 & 19.92 \\
\hline GRUH & 11.14 & 13.27 & 15.33 & 18.14 & 19.19 & 15.41 & 21.65 \\
\hline Average & 71.40 & 74.99 & 85.66 & 104.01 & 115.51 & \multirow{2}{*}{\multicolumn{2}{|c|}{90.32}} \\
\hline $\mathrm{CV}$ & 103.35 & 100.85 & 99.41 & 96.88 & 96.44 & & \\
\hline
\end{tabular}

From Table 4.3(a), it can be seen that the mean value of operating and administrative expenses is the highest for HDFC Ltd it is the lowest for CANFIN Home Finance Ltd. The mean value of operating and administrative expenses for the year 2015 is the highest and for the year 2011 is the lowest.

The coefficient of variation for HDFC Ltd is the least indicating that there is less variation in operating and administrative expenses over the study period and the coefficient of variation for CANFIN Home Finance Ltd is the highest indicating that there is more variation in operating and administrative expenses over the study period 2011-2015. The coefficient of variation of operating and administrative expenses for the year 2015 is the least indicating that the year is more consistent and the year 2011 coefficient of variation of operating and administrative expenses is the highest indicating that the year is inconsistent.

TABLE:4.3(b) Trend Analysis in Operating and Administrative Expenses

\begin{tabular}{|r|r|r|r|r|r|r|r|r|}
\hline \multirow{2}{*}{ YEAR } & \multicolumn{2}{|c|}{ LICHFL } & \multicolumn{2}{c|}{ CANFIN } & \multicolumn{2}{c|}{ HDFC } & \multicolumn{2}{c|}{ GRUH } \\
\cline { 2 - 9 } & Amount (Rs.) & \multicolumn{1}{|c|}{ AGR } & Amount (Rs.) & \multicolumn{1}{c|}{ AGR } & Amount (Rs.) & \multicolumn{1}{c|}{ AGR } & Amount (Rs.) & AGR \\
\hline $\mathbf{2 0 1 1}$ & 121.23 & 0 & 5.31 & 0 & 147.91 & 0 & 11.14 & 0 \\
\hline $\mathbf{2 0 1 2}$ & 136.56 & 12.65 & 5.94 & 11.86 & 144.2 & -2.51 & 13.27 & 19.12 \\
\hline $\mathbf{2 0 1 3}$ & 158.8 & 16.29 & 8.58 & 44.44 & 159.94 & 10.92 & 15.33 & 15.52 \\
\hline $\mathbf{2 0 1 4}$ & 184.46 & 16.16 & 15.61 & 81.93 & 197.84 & 23.70 & 18.14 & 18.33 \\
\hline $\mathbf{2 0 1 5}$ & 198.95 & 7.86 & 19.71 & 26.27 & 224.19 & 13.32 & 19.19 & 5.79 \\
\hline Average & & 10.59 & & 32.90 & & 9.08 & & 11.75 \\
\hline SD & & 6.84 & & 32.04 & & 10.63 & & 8.45 \\
\hline CV & & 64.62 & & 97.39 & & 116.98 & & 71.88 \\
\hline
\end{tabular}

It is found from the table 4.3(b) explains that the trend of operating and administrative expenses has increased from the base level of 0.00 to a maximum level of 16.29 in LICHFL, 81.93 in Can Fin Homes Ltd, 23.70 in HDFC Ltd and 19.12 in GRUH Fin Ltd. The index has come down the base year level for HDFC Ltd in the year 2012(-2.51). The operating and administrative expenses of select housing finance companies shows fluctuating trend during the period of study.

\subsection{Employee Expenses}

The housing finance companies spent amount for their employees, it includes salaries, bonus, contribution to provident fund and other funds, staff training and welfare expenses.

TABLE: 4.4(a) Analysis of Mean and Coefficient of Variation

\begin{tabular}{|c|c|c|c|c|c|c|c|}
\hline \multicolumn{8}{|c|}{ Employee Expenses } \\
\hline YEAR & 2011 & 2012 & 2013 & 2014 & 2015 & Average & $\mathbf{C V}$ \\
\hline LICHFL & 48.42 & 68.09 & 72.44 & 90.41 & 103.83 & 76.64 & 27.80 \\
\hline CANFIN & 8.2 & 10.82 & 10.86 & 15.73 & 17.9 & 12.70 & 31.34 \\
\hline HDFC & 131.78 & 168.5 & 197.02 & 246.19 & 279.18 & 204.53 & 28.88 \\
\hline GRUH & 11.55 & 15.72 & 19.68 & 24.18 & 31.73 & 20.57 & 37.91 \\
\hline Average & 49.99 & 65.78 & 75.00 & 94.13 & 108.16 & \multirow{2}{*}{\multicolumn{2}{|c|}{78.61}} \\
\hline $\mathbf{C V}$ & 115.01 & 111.31 & 114.36 & 113.39 & 111.02 & & \\
\hline
\end{tabular}

Table 4.4(a) shows that the mean value of employee expenses for HDFC Ltd is the maximum, while the mean value CANFIN Home Finance Ltd is the minimum. The mean value of employee expenses for the year 2015 is the highest and it is the lowest for the year 2011.

The coefficient of variation for LICHFL is the least indicating that there is less variation in employee expenses over the study period and it is having more variation in GRUH Finance Ltd. The coefficient of variation of employee expenses for the year 2015 is the lowest i.e., 111.02 indicating that the year is more consistent and the year 2011 is inconsistent because that the year coefficient of variation of employee expenses is the highest that is 115.01 . 
TABLE: 4.4(b) Trend Analysis in Employee Expenses

\begin{tabular}{|c|c|c|c|c|c|c|c|c|}
\hline \multirow[t]{2}{*}{ YEAR } & \multicolumn{2}{|c|}{ LICHFL } & \multicolumn{2}{|c|}{ CANFIN } & \multicolumn{2}{|l|}{ HDFC } & \multicolumn{2}{|l|}{ GRUH } \\
\hline & Amount (Rs.) & AGR & Amount (Rs.) & AGR & Amount (Rs.) & AGR & Amount (Rs.) & AGR \\
\hline 2012 & 68.09 & 40.62 & 10.82 & 31.95 & 168.5 & 27.86 & 15.72 & 36.10 \\
\hline 2014 & 90.41 & 24.81 & 15.73 & 44.84 & 246.19 & 24.96 & 24.18 & 22.87 \\
\hline 2015 & 103.83 & 14.84 & 17.9 & 13.80 & 279.18 & 13.40 & 31.73 & 31.22 \\
\hline Average & & 17.33 & & 18.19 & & 16.63 & & 23.08 \\
\hline $\mathrm{CV}$ & & 92.34 & & 108.82 & & 66.05 & & 60.24 \\
\hline
\end{tabular}

The Table 4.4(b) shows that the index of trends in employee expenses from the base year 2010-2011 to a maximum level of 40.62 in LICHFL, 44.84 in Can Fin Homes Ltd, 24.96 in HDFC Ltd and 36.10 in GRUH Fin Ltd. All these companies trend during the study period in fluctuating trend.

\subsection{Spread}

Spread is the difference between interest earned and interest paid and higher the difference is better for the housing finance companies. It is an important indicator of profitability and the performance of select housing finance companies.

TABLE: 4.5(a) Analysis of Mean and Coefficient of Variation

\begin{tabular}{|c|c|c|c|c|c|c|c|}
\hline \multicolumn{8}{|c|}{ Spread } \\
\hline YEAR & 2011 & 2012 & 2013 & 2014 & 2015 & Average & $\mathrm{CV}$ \\
\hline LICHFL & 1071.48 & 1759.42 & 1611.79 & 1722.88 & 2126.61 & 1658.44 & 22.97 \\
\hline CANFIN & 68.62 & 77.04 & 90.61 & 109.46 & 154.77 & 100.10 & 34.20 \\
\hline HDFC & 4275.2 & 5292.99 & 6175.99 & 7221.61 & 8113.7 & 6215.90 & 24.44 \\
\hline GRUH & 127.99 & 158.86 & 198.22 & 243.76 & 302.06 & 206.18 & 33.45 \\
\hline Average & 1385.82 & 1822.08 & 2019.15 & 2324.43 & 2674.29 & \multirow{2}{*}{\multicolumn{2}{|c|}{78.61}} \\
\hline $\mathrm{CV}$ & 142.90 & 133.92 & 141.47 & 143.93 & 139.68 & & \\
\hline
\end{tabular}

From Table 4.5(a), it can be seen that the mean value of spread is the highest for HDFC Ltd whereas it is the lowest for CANFIN Home Finance Ltd. For the year 2015 the mean value of spread is the highest and for the year 2011.

The coefficient of variation for LICHFL is the least indicating that there is less variation in spread over the study period 2011-2015 and the coefficient of variation for CANFIN Home Finance Ltd is having more variation in spread over the study period 2011-2015. The coefficient of variation of spread for the year 2012 is the lowest indicating that the year is more consistent one and the year 2014 is inconsistent because that the year coefficient of variation of spread is highest.

TABLE: 4.5(b) Trend Analysis in Spread

\begin{tabular}{|c|c|c|c|c|c|c|c|c|}
\hline \multirow[t]{2}{*}{ YEAR } & \multicolumn{2}{|l|}{ LICHFL } & \multicolumn{2}{|l|}{ CANFIN } & \multicolumn{2}{|l|}{ HDFC } & \multicolumn{2}{|l|}{ GRUH } \\
\hline & Amount (Rs.) & AGR & Amount (Rs.) & AGR & Amount (Rs.) & AGR & Amount (Rs.) & AGR \\
\hline 2011 & 1071.48 & 0 & 68.62 & 0 & 4275.2 & 0 & 127.99 & 0 \\
\hline 2012 & 1759.42 & 64.20 & 77.04 & 12.27 & 5292.99 & 23.81 & 158.86 & 24.12 \\
\hline 2013 & 1611.79 & -8.39 & 90.61 & 17.61 & 6175.99 & 16.68 & 198.22 & 24.78 \\
\hline 2014 & 1722.88 & 6.89 & 109.46 & 20.80 & 7221.61 & 16.93 & 243.76 & 22.97 \\
\hline 2015 & 2126.61 & 23.43 & 154.77 & 41.39 & 8113.7 & 12.35 & 302.06 & 23.92 \\
\hline Average & & 17.23 & & 18.42 & & 13.95 & & 19.16 \\
\hline SD & & 28.75 & & 15.09 & & 8.81 & & 10.73 \\
\hline $\mathbf{C V}$ & & 166.86 & & 81.96 & & 63.15 & & 56.00 \\
\hline
\end{tabular}

The Table 4.5(b) shows that the index of trends in spread has increased from base level of 0.00 to a maximum level of 64.20 in LICHFL, 41.39 in Can Fin Homes Ltd, 23.81 in HDFC Ltd and 24.78 in GRUH Fin Ltd. The index has come down the base year level in 2013 of spread of LICHFL (-8.39). These select housing finance companies trend in spread is in the fluctuating level.

\section{Findings}

a) The mean value of net profit, operating and administrative expenses, employee expenses and spread of HDFC Ltd is in maximum and also the mean value of total assets of LICHFL is in maximum.

b) The coefficient of variation for HDFC Ltd is least indicating that there is less variation in total assets, operating and administrative expenses, employee expenses and spread over the study period 2011-2015. 
c) The coefficient of variation for LICHFL is the least indicating that there is less variation in net profit, employee expenses and spread over the study period 2011-2015.

d) All the select housing finance companies trends are in fluctuating level.

\section{Conclusion}

The profitability management is a crucial importance of financial management decision. To stay in the market for a long period, financial institutions are totally depending upon their adequate earnings. The study about profitability of housing finance companies in India plays an important role in housing sector. The investors of a company are interested only when that the company earns profit otherwise they are not wish to invest their funds in this business. So components of profitability are employed by the management in order to assess how efficient operations required for their business operations.

\section{Journal Papers:}

\section{References}

[1]. $\quad$ Aswin Kumar Bhdalla et.al., "Profitability of Housing Finance Companies In India: A Bivariate Analysis of Selected HFCs", JIMS 8M, January - March 2009, pp.4-16.

[2]. Sohel Mehodi, "Liquidity and Profitability Analysis: a Case study of Delta Brac Housing Finance Corporation Limited", IOSR Journal of Business and Management (IOSR-JBM) e-ISSN: 2278-487X, p-ISSN: 2319-7668. Volume 15, Issue 5, 2014, pp 53-59.

[3]. Dr. Vikas Choudhary and Suman Tandon, "Performance Evaluation of Public Sector Banks in India", APJRBM,, Volume 1, Issue , Books: Oct 2010, pp.1-17.

[4]. Dr.S.P Gupta, Statistical Methods (S.Chand \& Sons, New Delhi, 2010).

[5]. C.R.Kothari, Research Methodology (New Age International (P) Ltd Publishers, New Delhi 2010). 